"adaptive radiation" and a comparative treatment of all kinds of pigeon behaviour, with the author's special interest, "displays", dealt with most extensively. These various discussions make one ask for more. How do the numbers of species in different parts of the world compare? What are the patterns of their subspeciation and of their superspeciation in the family as a whole? What are the ecological relationships where more than one species occurs? We shall hope that the author, who is better equipped than anybody else to supply the necessarily incomplete answers to such questions, will let us have them before long. This will further still more the author's intention of indicating, as he says, "what is not known" and hence is to be investigated.

R. E. Moreau

\section{CIRCANNIAN, NOT CIRCADIAN}

\section{Mammalian Hibernation III}

(Proceedings of the Third International Symposium, held at the University of Toronto, Toronto, Canada, September 13-16, 1965.) Edited by Kenneth C. Fisher, Albert R. Dawe, Charles P. Lyman, Edward Schönbaum and Frank E. South, jun. Pp. xiv +535. (Edinburgh and London: Oliver and Boyd, Ltd, 1967.) 126s. net.

There is an imposing list of contributors to this symposium and the book consists of 13 review papers which scan the major topics related to the subject of hibernation and also 12 original papers which were selected in an attempt to cover aspects of the subject which were not necessarily dealt with in the reviews.

Factors influencing the process of hibernation are well covered and the possibility of immediate environmental factors influencing either a yearly "circannian" rhythm or a circadian rhythm is discussed. Both these types of rhythm are examined and possible relationships between circadian rhythms and the annual cycle of hibernation are considered by F. Strumwasser, F. R. Schlechte and J. Streeter, who conclude that the annual cycle is a sequence of events each of which triggers off its succeeding one.

K. C. Fisher and J. F. Manery consider relationships between the hibernating animal's metabolism, particularly of fat, and the balance of water and electrolytes in the various body compartments. They bring out the interesting relationship between periodic arousal, involving heavy cost in energy, and the necessity to urinate. F. C. Kallen and H. A. Kanthor establish, however, in their work on the brown bat, that this animal voids urine during hibernation. The hibernator's energy metabolism is considered with particular reference to carbohydrates and two contributors concentrate on the significance of brown fat. As far as the latter is concerned it is clear that much more evidence is yet required on the ontogeny and phylogeny of this tissue before its relationship with other tissues, particularly white fat, can be established. In addition, the control of its thermogenesis is still far from being explained.

J. S. Willis, in considering the cold adaptation of tissues in hibernating mammals, suggests that answers to some of the problems of tissue adaptation might help to explain the evolution of hibernation and wide temperature tolerance. They might also help to answer the question of whether hibernators have re-acquired their temperature tolerance after it had been lost by their ancestors or whether it has been retained throughout the course of evolution in some adult birds and mammals and also in reptiles and newborn mammals. The absence of any definite relationship between the mechanisms involved in sleep and hibernation is made clear by W. C. Dement, and some interesting observations on host/parasite relationships in hibernating mammals are reviewed by J.P. Schmidt.

Other contributions which report changes as a result of hibernation include studies on the heart and circulation, caesium-137 metabolism in the ground squirrel, kidney function in bats, intestinal absorption of glucose in the hamster and the ground squirrel, and epithelial cell proliferation in the hamster and the dormouse.

This volume, which is dedicated to Professor Charles Kayser, is an extremely valuable reference book for readers with a wide range of interests related to hibernation. It has an extensive and up-to-date bibliography and the summaries, conclusions and reports of the discussions by the participants are extremely enlightening and stimulating. One feels that almost any current problem in this field will have been touched on in these discussions.

N. W. NowedL

\section{SYNTHESIS OF MITOCHONDRIA}

\section{The Biogenesis of Mitochondria}

By D. B. Roodyn and D. Wilkie. (Methuen's Monographs on Biological Subjects.) Pp. vi + 123. (London: Methuen and Co., Ltd, 1968.) 25s. net.

Some ten years ago many biochemists doubted the feasibility of unravelling the mechanism of synthesis of proteins. It is a measure of the rate of progress that a stimulating account can now be given of the first steps in understanding the biosynthesis of one of the more complex subcellular organelles. Roodyn and Wilkie have concentrated their attention almost entirely on the work of the past nine years and their review is replete with references to the most recent work. While this policy leads to the production of a stimulating monograph, it inevitably leads also to some uncritical citation of dubious evidence which could mislead the less expert reader. There is solid evidence that mitochondria contain DNA, but there is no good evidence that this has any sequence homology with nuclear DNA. It is established that isolated mitochondria can synthesize RNA and that mitochondrial RNA has sequence homology to mitochondrial DNA; there is, however, very little evidence that this RNA has an informational role in the synthesis of mitochondrial proteins and the logical attractiveness of the hypothesis does not necessarily strengthen the evidence. It is established that some mitochondrial proteins are coded for by nuclear genes and are synthesized outside the mitochondria. The nature of the protein synthesis which occurs inside mitochondria is scarcely understood, but at the present rate of progress this situation can change in a matter of months.

The extensive work on disassembly and re-assembly of mitochondrial components which has received considerable attention particularly in USA is hardly touched on, and the monographs by Racker and by Lehninger need to be studied to correct this omission.

Despite these criticisms the monograph by Roodyn and Wilkie serves as a valuable and clear introduction to the specialized work on protein and nucleic acid synthesis in mitochondria. It is perhaps a measure of both the value and of the potential danger of an attractive hypo. thesis that it can both guide research in one direction and at the same time inhibit it in another. Mendelian genetics and recent developments in molecular biology have combined to emphasize the supreme importance of the nucleus in determining cell heredity and protein specificity, yet the germ cell frequently contains more cytoplasmic DNA than nuclear DNA. Until recently this DNA has been shrugged off as storage DNA, but recent work on mitochondria and on mitochondrial inheritance warns that this attitude is no longer tenable. Roodyn and Wilkie give a clear account of what is known concerning the genetics of yeast mitochondria and of the prospects opened up by mutation and recombination among mitochondrial "genes". This work prompts the question-are all the mitochondria of one cell identical or is there a spectrum of mitochondria ? It is established that mitochondrial DNA can undergo changes analogous to those which occur in mutation; what is not clear is the related question: 